\title{
Effects of increasing the dose of ropivacaine on vertical infraclavicular block using neurostimulation
}

\author{
Chun Woo Yang ${ }^{1}$, Po Soon Kang ${ }^{2}$, Hee Uk Kwon², Kyu Chang Lee ${ }^{3}$, Myeong Jong Lee ${ }^{3}$, \\ Hye Young Kim ${ }^{3}$, Eun Kyung Choi ${ }^{3}$, Hyun Kyoung Lim $^{4}$, and Chul Woung Kim ${ }^{5}$ \\ Department of Anesthesiology and Pain Medicine, ${ }^{1}$ Jeju Halla General Hospital, Jeju, ${ }^{2}$ Konyang University Hospital, Daejeon, \\ ${ }^{3}$ Chungju Hospital, Konkuk University School of Medicine, Chungju, ${ }^{4}$ College of Medicine, Inha University, Incheon, \\ ${ }^{5}$ Department of Preventive Medicine, School of Medicne, Chungnam National University, Daejeon, Korea
}

Background: Use of an infraclavicular block is appropriate for surgery of the upper limb. However, it does not consistently block the entire brachial plexus. The aim of this study was to investigate whether increasing the dose of ropivacaine could enhance the success rate, onset time, and efficacy of the sensory and motor block during the use of a vertical infraclavicular block using neurostimulation in upper limb surgery.

Methods: Two hundreds and ten patients were prospectively randomized into three groups: Group 1 (30 $\mathrm{ml}$ of $0.5 \%$ ropivacaine; $\mathrm{n}=70$ ), Group 2 ( $40 \mathrm{ml}$ of $0.5 \%$ ropivacaine; $\mathrm{n}=70$ ), and Group 3 ( $40 \mathrm{ml}$ of $0.75 \%$ ropivacaine; $\mathrm{n}=70$ ). Patients in each group received a vertical infraclavicular block using neurostimulation and obtained a distal motor response of the ulnar or median nerve. Recorded outcome measures included block success rate, onset time, sensory and motor blocks, and adverse events.

Results: No differences were found in the block success rate among the three groups $(92.8 \%, 97.1 \%$, and $94.2 \%$ for Groups 1, 2, and, 3, respectively; $\mathrm{P}=0.346)$. There were no significant differences in onset time $(\mathrm{P}=0.225)$ among groups, nor was there enhancement in the sensory block, but the motor block was enhanced. Local anesthetic toxicity was observed in five female patients from group $3(\mathrm{P}=0.006)$.

Conclusions: Although the efficacy of the motor block was significantly improved, success rate, onset time, and efficacy of sensory block were not enhanced significantly among groups despite differences in volume and volume/ concentration of the local anesthetic. (Korean J Anesthesiol 2012; 63: 36-42)

Key Words: Brachial plexus, Nerve block, Ropivacaine, Toxicity.

Received: September 27, 2011. Revised: 1st, December 8, 2011; 2nd, December 27, 2011; 3rd, January 4, 2012; 4th, January 18, 2012. Accepted: January 19, 2012.

Corresponding author: Po Soon Kang, M.D., Department of Anesthesiology and Pain Medicine, School of Medicine, Konyang University, 685, Gasuwon-dong, Seo-gu, Daejeon 302-718, Korea. Tel: 82-42-600-9317, Fax: 82-42-545-2132, E-mail: kangpo1026@hanmail.net

(C) This is an open-access article distributed under the terms of the Creative Commons Attribution Non-Commercial License (http:// creativecommons.org/licenses/by-nc/3.0/), which permits unrestricted non-commercial use, distribution, and reproduction in any medium, provided the original work is properly cited. 


\section{Introduction}

An infraclavicular block can be used to provide effective surgical anesthesia of the upper limb. However, the success rate of the infraclavicular block varies widely in the range of $40-97 \%[1,2]$. Various factors may affect the success rate of the infraclavicular block, such as the use of a multiple injection technique [3], the type of evoked motor response [4], the use of ultrasound guidance [5], and operator experience. Whether increasing the dose by volume, concentration, or a combination of the two of local anesthetics results in a higher success rate remains controversial in clinical settings.

Different combinations of volumes and concentrations of local anesthetics have been used to block the brachial plexus. In our institution, we routinely use $30 \mathrm{ml}$ of local anesthetics and $0.5 \%$ ropivacaine for the infraclavicular block. In our previous study [6], the same volume $(30 \mathrm{ml})$ of $0.75 \%$ and $0.5 \%$ ropivacaine produced similar infraclavicular block success rates and efficacy. Our hypothesis is that a further increase in the dose of local anesthetics (to the recommended maximum [7]) by volume ( $40 \mathrm{ml}$ of $0.5 \%$ ropivacaine) or volume/concentration (40 $\mathrm{ml}$ of $0.75 \%$ ropivacaine) will yield a higher infraclavicular block success rate using neurostimulation.

The primary objective of this study was to evaluate whether increasing the dose of ropivacaine by volume or volume/ concentration enhances the success rate of the vertical infraclavicular block. The secondary outcomes included block onset time, efficacy of the sensory and motor block, and adverse events.

\section{Materials and Methods}

After approval by our local ethical committee, all patients provided written informed consent. Two hundreds and ten patients (ages 18-70 years, American Society of Anesthesiologists physical status [ASA] I-III) scheduled for surgical procedures of the upper extremities were prospectively randomized using sealed envelopes that were opened just before the patients were included. Exclusion criteria included any contraindication to regional anesthesia, pregnancy, allergy to local anesthetics, or neurological disorders. Patients were randomly assigned to three groups: Group $1(n=70)$ received $30 \mathrm{ml}$ of $0.5 \%$ ropivacaine (Naropin ${ }^{\circledR}$, AstraZeneca, Sweden), Group $2(\mathrm{n}=70)$ received $40 \mathrm{ml}$ of $0.5 \%$ ropivacaine, and Group $3(n=70)$ received $40 \mathrm{ml}$ of $0.75 \%$ ropivacaine.

For organizational and data collection purposes, blocks were performed 60 min before surgery in the recovery room. Standard monitoring was used throughout the procedure (electrocardiogram, noninvasive blood pressure, and pulse oximetry). No premedication was administered before the block. All blocks were performed by the same anesthesiologist using a nerve stimulator (Stimuplex ${ }^{\circledR}$ HNS 12, B. Braun, Germany) and a 22-gauge, 50-mm insulated needle (Stimuplex ${ }^{\circledR}$ A, B. Braun, Germany). The initial nerve stimulator settings were $1.5 \mathrm{~mA}, 0.1$ $\mathrm{ms}$, and $1 \mathrm{~Hz}$.

The vertical infraclavicular block was performed with the patient in the supine position with their upper arm to their side and their palm facing up. After landmarks were identified, the puncture site was marked half way between the jugular notch and the ventral process of the acromion. After subcutaneous infiltration with $2 \mathrm{ml}$ of $1 \%$ lidocaine, the needle was initially introduced absolutely vertical to the horizontal plane. The needle was advanced until a distal motor response of the hand or wrist was elicited. If no response was elicited upon needle insertion, the needle was reintroduced, with a slight deviation in the caudal, cranial, or lateral (not medial) direction until a motor response was obtained.

Needle position was considered adequate when a distal motor response of the median or ulnar nerve was obtained (flexion of the wrist and/or fingers) and remained visible at a current intensity of $\leq 0.5-\mathrm{mA}$. Predetermined ropivacaine was injected slowly in 5-ml increments with intermittent aspiration.

After local anesthetic administration, a blinded observer evaluated the block. Sensory block was assessed in the distribution of radial, median, ulnar, musculocutaneous, and medial antebrachial cutaneous nerve by cold testing using alcohol swabs with the following scale: $0=$ normal sensation, $1=$ reduced sensation to cold, and $2=$ no sensation to cold. Sensory blocks were evaluated every $1 \mathrm{~min}$ until $50 \mathrm{~min}$ or a complete sensory block was achieved. Time 0 (zero) was designated the end of the local anesthetic injection. A block was defined as successful when a cold response was abolished in all five nerves distal to the elbow within 50 min after the injection of the drug. The block was considered incomplete if analgesia was not present in one or more of the nerve distributions within $50 \mathrm{~min}$. The time between the end of the injection and the development of a successful block was defined as the block onset time.

Motor blocks were evaluated every $10 \mathrm{~min}$ until $50 \mathrm{~min}$ or complete motor block was achieved. The motor block was evaluated using forearm flexion, thumb abduction, thumb opposition, and thumb adduction (for the musculocutaneous, radial, median, and ulnar nerve, respectively) and scored as follows: $0=$ no change, $1=$ reduced power, and $2=$ complete loss of power.

After the 50 min study period, the patient was taken to the operating room. If the sensory and motor blocks were complete prior to the 50 min mark, surgery commenced early. Those patients who requested sedation for the surgery was administered a continuous IV infusion of propofol at $2-3 \mathrm{mg} / \mathrm{kg} / \mathrm{h}$. If a patient complained of pain at the surgical site, the block was 
supplemented by the continuous infusion of propofol at $2-4$ $\mathrm{mg} / \mathrm{kg} / \mathrm{h}$ and sufentanil $0.1-0.3 \mu \mathrm{g} / \mathrm{kg}$ IV. If this measure did not provide adequate pain control, then general anesthesia was induced.

Surgical procedures, surgery time, tourniquet time, and tourniquet pain were recorded. Adverse events, such as vascular puncture, local anesthetic toxicity, Horner's syndrome, dyspnea, and pneumothorax were also noted.

The success rate at 50 min was chosen as the primary endpoint. Assumptions for the sample-size analysis were based on the success rate of our previous study [8], in which a vertical infraclavicular block yielded a success rate of $82 \%$. A cohort of 66 subjects would have $80 \%$ power to detect a clinically important (15\%) difference in success rate among the groups upon acceptance of an $\alpha$ error of $5 \%$ and a $\beta$ error of $20 \%$. Four extra patients were included to allow for possible dropouts.

Statistical analyses were performed using SPSS $12.0 \mathrm{KO}$ (SPSS Inc., Chicago, US). Continuous variables were presented as mean (SD) or median (range) according to the data distribution. Quantitative variables in the three study groups were compared using one-way analysis of variance (ANOVA) with Bonferroni's correction in the post-hoc analyses. The Kruskal-Wallis test was used as a non-parametric alternative. Categorical variables were presented as number of patients (\%). Comparison of categorical variables was carried out using the $\chi^{2}$ test (Fisher's exact test, if necessary). A value of $\mathrm{P}<0.05$ was considered statistically significant.

\section{Results}

A total of 210 patients were recruited. It was not possible to elicit a typical median or ulnar nerve response in one patient

Table 1. Demographic and Surgical Data

\begin{tabular}{lccc}
\hline & $\begin{array}{c}\text { Group 1 } \\
(\mathrm{n}=69)\end{array}$ & $\begin{array}{c}\text { Group 2 } \\
(\mathrm{n}=70)\end{array}$ & $\begin{array}{c}\text { Group 3 } \\
(\mathrm{n}=70)\end{array}$ \\
\hline Age (yr) & $44 \pm 13$ & $44 \pm 13$ & $46 \pm 15$ \\
Sex (M/F) & $40 / 29$ & $43 / 27$ & $42 / 28$ \\
Height (cm) & $165 \pm 8$ & $164 \pm 7$ & $165 \pm 10$ \\
Weight (kg) & $64 \pm 11$ & $63 \pm 9$ & $66 \pm 12$ \\
ASA physical status (I/II/III) & $45 / 25 / 0$ & $50 / 20 / 0$ & $51 / 18 / 1$ \\
Type of surgery (n) & & & \\
$\quad$ Hand & 22 & 33 & 25 \\
$\quad$ Forearm & 39 & 32 & 31 \\
$\quad$ Elbow & 8 & 5 & 14 \\
Tourniquet times (min) & $54 \pm 34$ & $48 \pm 33$ & $51 \pm 33$ \\
Surgical time (min) & $64 \pm 42$ & $58 \pm 38$ & $60 \pm 36$ \\
\hline
\end{tabular}

Values are mean \pm SD or number of patients. ASA: American Society of Anesthesiologists. Group 1: infraclavicular block with $30 \mathrm{ml}$ of $0.5 \%$ ropivacaine. Group 2: infraclavicular block with $40 \mathrm{ml}$ of $0.5 \%$ ropivacaine. Group 3: infraclavicular block with $40 \mathrm{ml}$ of $0.75 \%$ ropivacaine. in Group 1, so this patient was excluded from the study. No difference was found among groups in regard to demographic and surgical data (Table 1). Table 2 shows the block success and failure rates. The overall success rate was $94.7 \%$. The success rate did not differ significantly among groups, although it was higher in Groups 2 and 3 than Group $1(\mathrm{P}=0.346)$. Blocks sufficient for surgery and supplementation were comparable among groups. One patient in Group 1 needed general anesthesia due to complete block failure. Three patients in Group 1 and two patients in Group 2 reported tourniquet pain (not statistically significant). Intraoperative sedation was requested by 14,8 , and 15 patients for Group 1, 2, and 3, respectively (not statistically significant).

Block onset time was $9(2-45), 8(2-48)$, and $6(2-46)$ min for Groups 1, 2, and 3, respectively. Although onset time tended to be shorter in Group 3, there was no significant difference among groups $(P=0.225)$. Fig. 1 and 2 show the percentage of successful sensory blocks by nerve and the percentage of patients in whom a complete sensory block was achieved over time, respectively. There were no statistically significant differences among groups in these outcomes.

Fig. 3 shows the percentage of complete motor block achieved by nerve within 50 -min study period. Significant differences among groups were found in the median (at 10, 20, 30, and $40 \mathrm{~min}$ ), ulnar (at 20,30, 40, and $50 \mathrm{~min}$ ), and musculocutaneous (at 10 and $20 \mathrm{~min}$ ) nerves among groups $(\mathrm{P}<0.05)$. Fig. 4 shows the percentage of patients in whom a complete motor block was achieved over time. There were significant differences among groups in the percentage of achieved complete motor blocks over time $(\mathrm{P}<0.05)$.

Table 3 shows the adverse events observed in this study. No differences were found in vascular puncture, Horner's syndrome, and dyspnea among groups. Signs and symptoms of local anesthetic toxicity were observed in five patients in Group 3 (P $=0.006$ ). Of those, one patient developed generalized tonic - clonic seizure activity. All six patients were administered propofol and recovered without any complications.

Table 2. Block Success and Failure Rates

\begin{tabular}{lccc}
\hline & $\begin{array}{c}\text { Group 1 } \\
(\mathrm{n}=69)\end{array}$ & $\begin{array}{c}\text { Group 2 } \\
(\mathrm{n}=70)\end{array}$ & $\begin{array}{c}\text { Group 3 } \\
(\mathrm{n}=70)\end{array}$ \\
\hline Successful blocks & $64(92.8)$ & $68(97.1)$ & $66(94.2)$ \\
Blocks sufficient for surgery & $66(95.7)$ & $68(97.1)$ & $69(98.5)$ \\
Supplementation & $2(2.9)$ & $2(2.9)$ & $1(1.4)$ \\
Failure & $1(1.4)$ & - & - \\
\hline
\end{tabular}

The values are the number of patients (\%). Group 1: infraclavicular block with $30 \mathrm{ml}$ of $0.5 \%$ ropivacaine. Group 2: infraclavicular block with $40 \mathrm{ml}$ of $0.5 \%$ ropivacaine. Group 3: infraclavicular block with $40 \mathrm{ml}$ of $0.75 \%$ ropivacaine. 

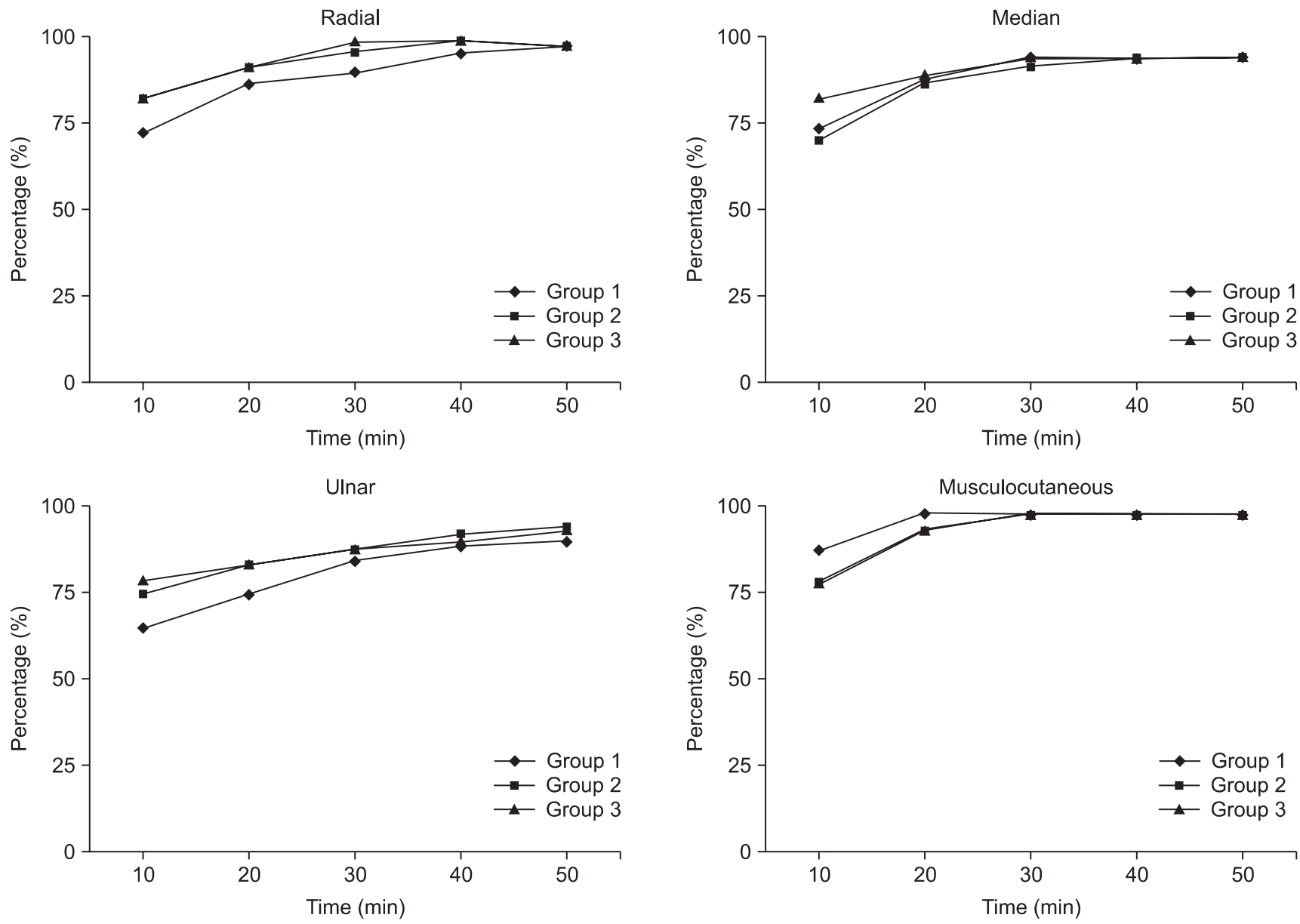

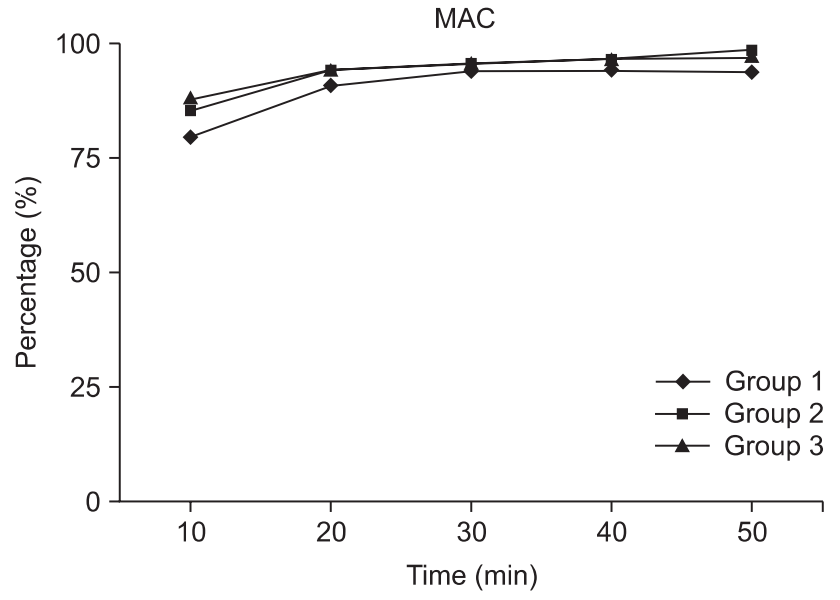

\section{Discussion}

In this randomized study, we show that increasing the dose of ropivacaine by volume or volume/concentration does not necessarily lead to any clinically significant advantages with regard to vertical infraclavicular block. Importantly, increasing the doses of ropivacaine $(300 \mathrm{mg}$ ) can induce systemic toxicity of the local anesthetic in female patients.

The success rates of our previous studies were $70-88 \%$ $[6,8,9]$. In this study, we hypothesize that increasing the dose of local anesthetics will enhance the infraclavicular block success rate and efficacy. Therefore, we increased the dose of local anesthetics by increasing only volume (two variables) and then by increasing the concentration as well (three variables). 


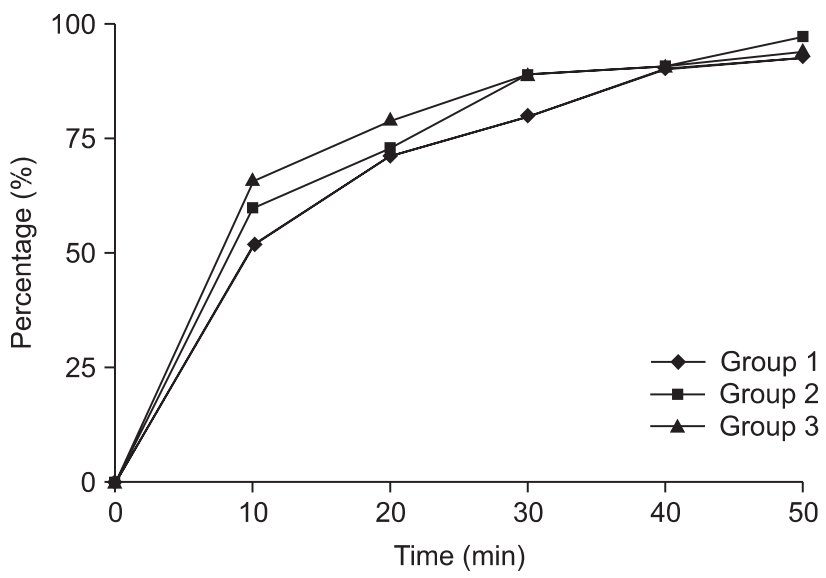

Fig. 2. Percentage of patients with complete sensory block over time. Group 1: infraclavicular block with $30 \mathrm{ml}$ of $0.5 \%$ ropivacaine. Group 2: infraclavicular block with $40 \mathrm{ml}$ of $0.5 \%$ ropivacaine. Group 3: infraclavicular block with $40 \mathrm{ml}$ of $0.75 \%$ ropivacaine.
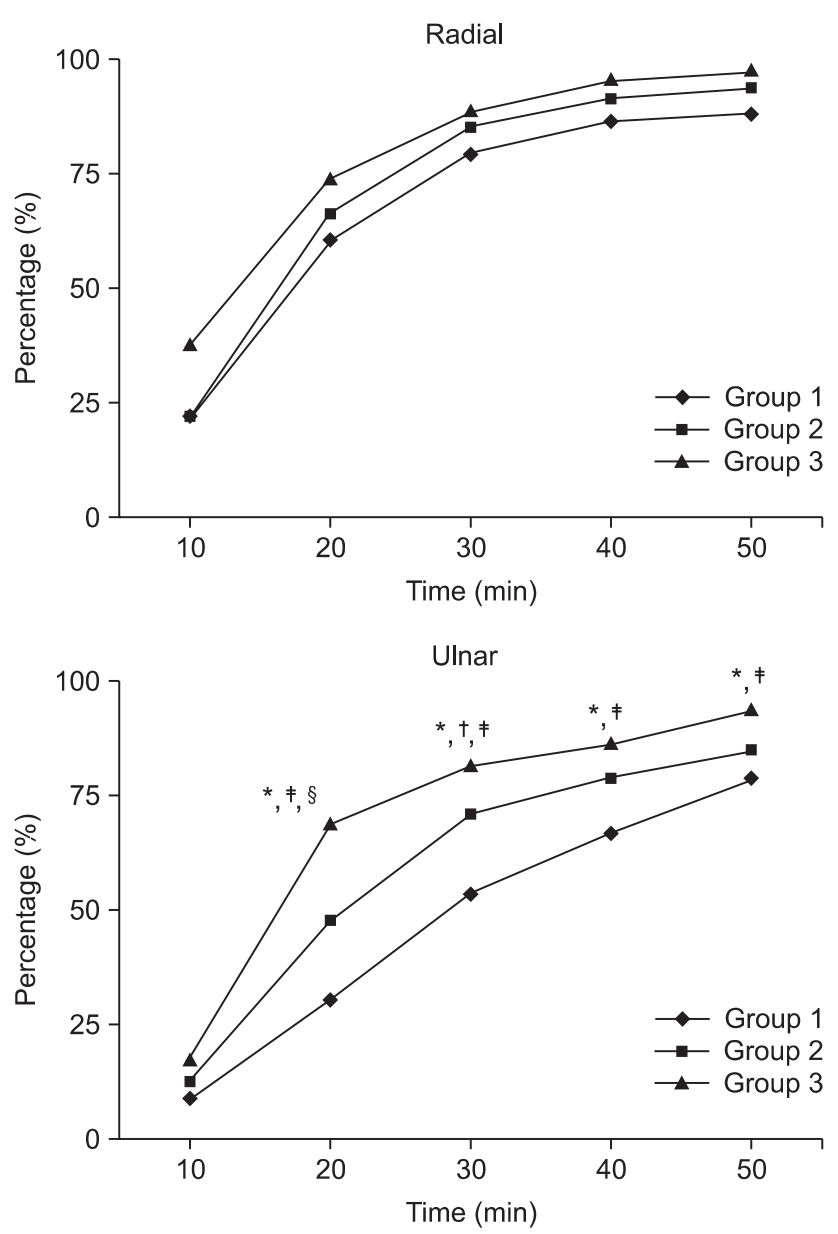

The success rate was higher in Groups 2 (97.1\%) and 3 (94.2\%) than in Group 1 (92.8\%), although there were no significant differences among groups. Tran de et al. [10] recently reported a minimum effective volume of $35 \mathrm{ml}$ for ultrasound-guided infraclavicular block in $90 \%$ of patients. Compared with neurostimulation, ultrasound can reduce local anesthetic requirements. Therefore, it is our recommendation that use of $40 \mathrm{ml}$ of $0.5 \%$ ropivacaine is more suitable for vertical infraclavicular blocks using neurostimulation considering the block efficacy and toxicity of local anesthetics.

The effects of increasing the dose of local anesthetics on success rate or efficacy of the brachial plexus block remain controversial. Vester-Andersen et al. [11] reported that when concentration was held constant, increasing doses by volume resulted in no difference in sensory or motor anesthesia. When volume was held constant, sensory blocks were 70$100 \%$ successful in all nerve groups regardless of concentration increases [12]. In contrast, Casati et al. [13] reported that
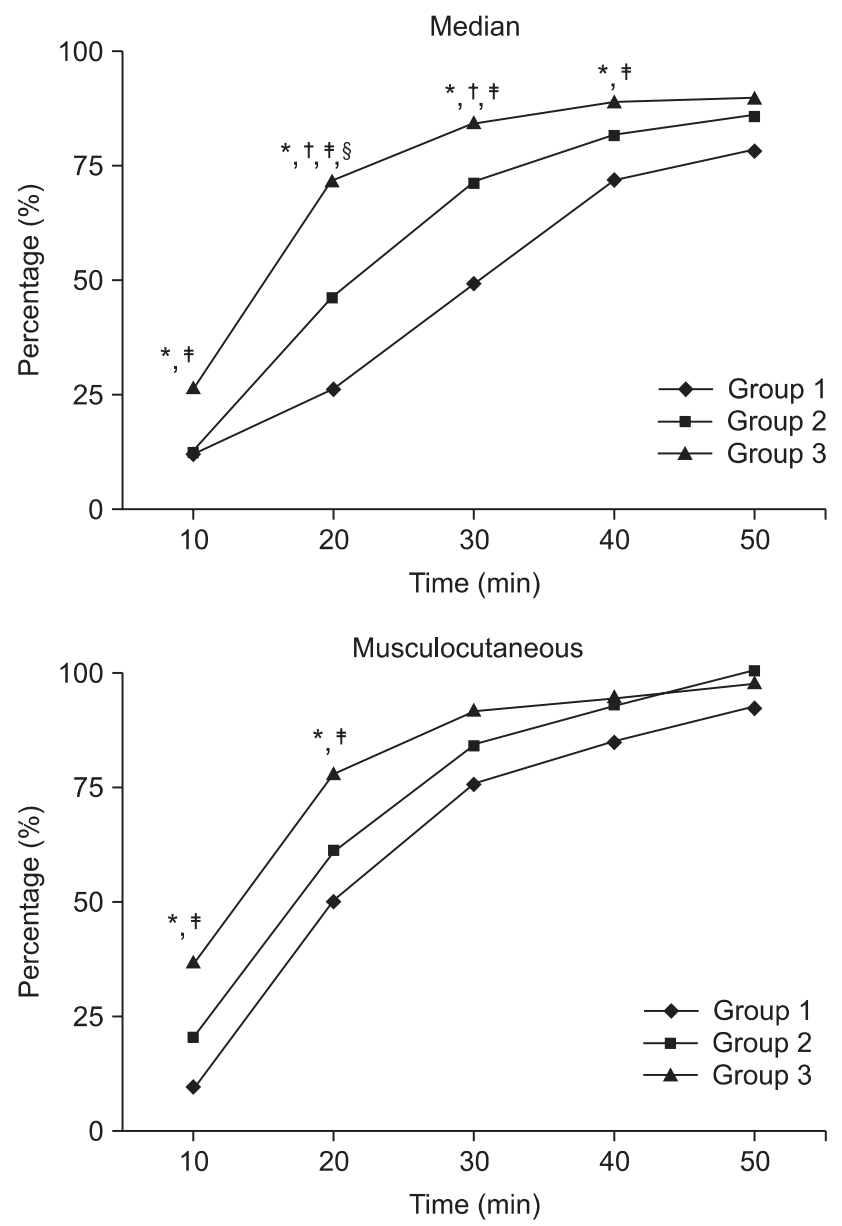

Fig. 3. Percentage of patients with complete motor block for each nerve over time. Group 1: infraclavicular block with $30 \mathrm{ml}$ of $0.5 \%$ ropivacaine. Group 2: infraclavicular block with $40 \mathrm{ml}$ of $0.5 \%$ ropivacaine. Group 3: infraclavicular block with $40 \mathrm{ml}$ of $0.75 \%$ ropivacaine. *P $<0.05$ among groups. ${ }^{\dagger} \mathrm{P}<0.05$ between groups 1 and $2 .{ }^{\ddagger} \mathrm{P}<0.05$ between groups 1 and $3 .{ }^{\S} \mathrm{P}<0.05$ between groups 2 and 3. 


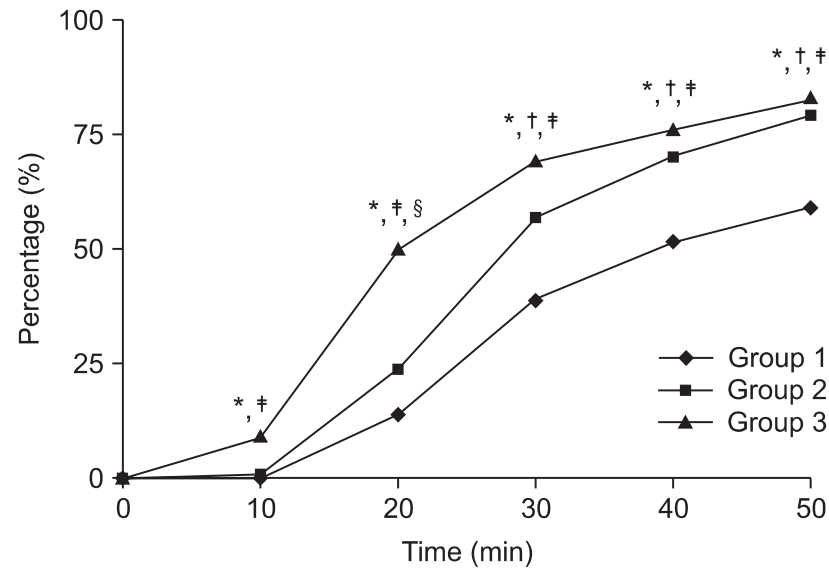

Fig. 4. Percentage of patients with complete motor block over time. Group 1: infraclavicular block with $30 \mathrm{ml}$ of $0.5 \%$ ropivacaine. Group 2: infraclavicular block with $40 \mathrm{ml}$ of $0.5 \%$ ropivacaine. Group 3: infraclavicular block with $40 \mathrm{ml}$ of $0.75 \%$ ropivacaine. $* \mathrm{P}<0.05$ among groups. ${ }^{\dagger} \mathrm{P}<0.05$ between group 1 and group $2 .{ }^{\dagger} \mathrm{P}<0.05$ between group 1 and group $3 .{ }^{\S} \mathrm{P}<0.05$ between group 2 and group 3 .

increasing the dose of local anesthetics by increasing the concentration without changing the injected volume shortened sensory and motor onset times but did not increase the block success rate.

In this study, why increasing the dose of local anesthetics by volume or volume/concentration does not lead to a higher success rate remains unclear. It may be caused by the fact that a relatively high dose of local anesthetic is already injected. If corrected for weights, then perhaps a difference in success rate would have been detected. Another reason is that the septa around the cords can prevent effective spread of local anesthetic. Morimoto et al. [14] reported that the presence of septae within the neurovascular sheath influenced the pattern of local anesthetic spread.

In this study, increasing dose enhanced motor block efficacy. Compared with Group 1, increasing dose, especially Group 3, produced a higher percentage of patients with complete motor block for each nerve (except the radial) and all nerves over time. These results were consistent with those of the previous study [13], which may be due to the fact that more local anesthetic molecules in Groups 2 and 3 in the current study were available to penetrate the peripheral nerves per unit time.

There is considerable variability in the arterial plasma concentrations of ropivacaine after injection for a vertical infraclavicular block, but peak plasma concentrations occur at 20$30 \mathrm{~min}$ [15]. In this study, neurologic toxicity occurred in all female patients $16-30$ min after block induction, indicating rapid absorption of a relatively large dose of ropivacaine $5-6.38$ $\mathrm{mg} / \mathrm{kg})$.

We are not aware of any reason why females should be sus-
Table 3. Adverse Events

\begin{tabular}{llcl}
\hline & $\begin{array}{c}\text { Group 1 } \\
(\mathrm{n}=69)\end{array}$ & $\begin{array}{c}\text { Group 2 } \\
(\mathrm{n}=70)\end{array}$ & $\begin{array}{c}\text { Group 3 } \\
(\mathrm{n}=70)\end{array}$ \\
\hline Vascular puncture & $7(10)$ & $4(6)$ & $9(13)$ \\
LA toxicity* & $0(0)$ & $0(0)$ & $5(7)$ \\
Horner syndrome & $2(3)$ & $6(9)$ & $4(6)$ \\
Dyspnea & $1(1)$ & $0(0)$ & $3(4)$ \\
\hline
\end{tabular}

The values are the number of patients (\%). LA: local anesthetic. Group 1: infraclavicular block with $30 \mathrm{ml}$ of $0.5 \%$ ropivacaine. Group 2: infraclavicular block with $40 \mathrm{ml}$ of $0.5 \%$ ropivacaine. Group 3: infraclavicular block with $40 \mathrm{ml}$ of $0.75 \%$ ropivacaine. ${ }^{*} \mathrm{P}<0.05$ among groups.

ceptible to local ropivacaine toxicity, but there are two possible explanations: the pharmacokinetic difference between men and women, or that $300 \mathrm{mg}$ of ropivacaine may have been excessive in some patients. Several previous reports [16-19] have stated that $300 \mathrm{mg}$ of local ropivacaine could produce systemic toxicity. It is difficult to recommend a safe maximum dose of ropivacaine, but doses of local anesthetics should be block-specific, site-specific, and patient-specific [7].

Epinephrine is often added to local anesthetic agents to reduce systemic absorption by causing local vasoconstriction and potentially limit systemic local anesthetic toxicity by reducing time-to-peak concentrations and peak plasma concentrations. However, Hickey et al. [20] reported that the addition of epinephrine did not alter the pharmacokinetic properties of ropivacaine when used for subclavian perivascular brachial plexus blocks. Therefore, we did not add epinephrine to ropivacaine in this study.

This study had some limitations. First, we performed infraclavicular blocks using neurostimulation. This possibly reflects a deficit in placement of local anesthetic, i.e., how much of the injectate in each case was actually delivered around the cords. Without the use of ultrasound, we cannot know whether the local anesthetic was placed accurately, a deficit of many older studies examining dose response for peripheral nerve blocks. Second, a single anesthesiologist performed all of the blocks. Although this eliminates inter-operator variability, it might limit the generalizability of the results. Third, the type of evoked distal response is an important factor that influences overall infraclavicular block success. In this study, we decided to accept only evoked responses of the median or ulnar nerves in the hand or wrist as valid to avoid confounding factors. Our own experience and that of others [21] have shown that a median or ulnar nerve response yields a higher success rate than a radial nerve response. However, these findings need to be confirmed by a randomized study to further influence the type of evoked distal motor responses on success rate during vertical infraclavicular blocks. 
In conclusion, the results of this prospective, randomized, double-blind study demonstrate that increasing the doses of ropivacaine by volume or volume/concentration does not improve sensory block success rate, onset time, or efficacy; rather it improved motor block efficacy only during vertical infraclavicular blocks. It is our recommendation that the use of $40 \mathrm{ml}$ of $0.5 \%$ ropivacaine may be more appropriate for vertical infraclavicular blocks considering block efficacy and the toxicity of local anesthetics.

\section{References}

1. Gaertner E, Estebe JP, Zamfir A, Cuby C, Macaire P. Infraclavicular plexus block: multiple injection versus single injection. Reg Anesth Pain Med 2002; 27: 590-4.

2. Borgeat A, Ekatodramis G, Dumont C. An evaluation of the infraclavicular block via a modified approach of the Raj technique. Anesth Analg 2001; 93: 436-41.

3. Rodriguez J, Barcena M, Lagunilla J, Alvarez J. Increased success rate with infraclavicular brachial plexus block using a dual-injection technique. J Clin Anesth 2004; 16: 251-6.

4. Lecamwasam H, Mayfield J, Rosow L, Chang Y, Carter C, Rosow C. Stimulation of the posterior cord predicts successful infraclavicular block. Anesth Analg 2006; 102: 1564-8.

5. Dingemans E, Williams SR, Arcand G, Chouinard P, Harris P, Ruel M, et al. Neurostimulation in ultrasound-guided infraclavicular block: a prospective randomized trial. Anesth Analg 2007; 104: 1275-80.

6. Park JM, Jung SM, Cho CK, Lim YS, Ku JH, Heo YM, et al. A clinical comparison of vertical infraclavicular brachial plexus block using $0.75 \%$ or $0.5 \%$ ropivacaine for upper limb surgery. Korean J Anesthesiol 2009; 57: 572-8.

7. Rosenberg PH, Veering BT, Urmey WF. Maximum recommended doses of local anesthetics: a multifactorial concept. Reg Anesth Pain Med 2004; 29: 564-75.

8. Yang CW, Kwon HU, Cho CK, Jung SM, Kang PS, Park ES, et al. A comparison of infraclavicular and supraclavicular approaches to the brachial plexus using neurostimulation. Korean J Anesthesiol 2010; 58: 260-6.

9. Cho CK, Kim JY, Jung SM, Kwon HU, Kang PS, Kim CW, et al. Comparison of vertical infraclavicular brachial plexus block with $0.5 \%$ levobupivacaine and $0.5 \%$ ropivacaine for upper limb surgery. Korean J Anesthesiol 2009; 56: 162-8.

10. Tran de QH, Dugani S, Dyachenko A, Correa JA, Finlayson RJ. Minimum effective volume of lidocaine for ultrasound-guided infraclavicular block. Reg Anesth Pain Med 2011; 36: 190-4.

11. Vester-Andersen T, Husum B, Lindeburg T, Borrits L, Gothgen I. Perivascular axillary block IV: blockade following 40,50 or $60 \mathrm{ml}$ of mepivacaine $1 \%$ with adrenaline. Acta Anaesthesiol Scand 1984; 28 : 99-105.

12. Vester-Andersen T, Eriksen C, Christiansen C. Perivascular axillary block III: blockade following $40 \mathrm{ml}$ of $0.5 \%, 1 \%$ or $1.5 \%$ mepivacaine with adrenaline. Acta Anaesthesiol Scand 1984; 28: 95-8.

13. Casati A, Fanelli G, Aldegheri G, Berti M, Colnaghi E, Cedrati V, et al. Interscalene brachial plexus anaesthesia with $0.5 \%, 0.75 \%$ or $1 \%$ ropivacaine: a double-blind comparison with $2 \%$ mepivacaine. $\mathrm{Br} \mathrm{J}$ Anaesth 1999; 83: 872-5.

14. Morimoto M, Popovic J, Kim JT, Kiamzon H, Rosenberg AD. Case series: Septa can influence local anesthetic spread during infraclavicular brachial plexus blocks. Can J Anaesth 2007; 54: 1006-10.

15. Rettig HC, Lerou JG, Gielen MJ, Boersma E, Burm AG. The pharmacokinetics of ropivacaine after four different techniques of brachial plexus blockade. Anaesthesia 2007; 62:1008-14.

16. Ala-Kokko TI, Lopponen A, Alahuhta S. Two instances of central nervous system toxicity in the same patient following repeated ropivacaine-induced brachial plexus block. Acta Anaesthesiol Scand 2000; 44: 623-6.

17. Kimura Y, Kamada Y, Kimura A, Orimo K. Ropivacaine-induced toxicity with overdose suspected after axillary brachial plexus block. J Anesth 2007; 21: 413-6.

18. Satsumae T, Tanaka M, Saito S, Inomata S. Convulsions after ropivacaine $300 \mathrm{mg}$ for brachial plexus block. Br J Anaesth 2008; 101: 8602.

19. Yang CW, Kang PS, Kwon HU, Lim DJ. High dose ropivacaineinduced toxicity after infraclavicular block. Korean J Anesthesiol 2012; 62: 96-7.

20. Hickey R, Blanchard J, Hoffman J, Sjovall J, Ramamurthy S. Plasma concentrations of ropivacaine given with or without epinephrine for brachial plexus block. Can J Anaesth 1990; 37: 878-82.

21. Moayeri N, Renes S, van Geffen GJ, Groen GJ. Vertical infraclavicular brachial plexus block: needle redirection after elicitation of elbow flexion. Reg Anesth Pain Med 2009; 34: 236-41. 